E. Bakhtadze $\cdot$ H. Borg • G. Stenström • P. Fernlund •

H. J. Arnqvist · A. Ekbom-Schnell • J. Bolinder •

J. W. Eriksson · S. Gudbjörnsdottir · L. Nyström •

L. C. Groop - G. Sundkvist

\title{
HLA-DQB1 genotypes, islet antibodies and beta cell function in the classification of recent-onset diabetes among young adults in the nationwide Diabetes Incidence Study in Sweden
}

Received: 28 October 2005 / Accepted: 16 March 2006 / Published online: 31 May 2006

(C) Springer-Verlag 2006

\begin{abstract}
Aims/hypothesis: The World Health Organization considers an aetiological classification of diabetes to be essential. The aim of this study was to evaluate whether $H L A-D Q B 1$ genotypes facilitate the classification of diabetes as compared with assessment of islet antibodies by investigating young adult diabetic patients. Subjects and methods: Blood samples were available at diagnosis
\end{abstract}

E. Bakhtadze · H. Borg · L. C. Groop · G. Sundkvist $(\bowtie)$ Department of Clinical Sciences Malmö,

Division of Endocrinology and Diabetes, Lund University, Malmö University Hospital, 20502 Malmö, Sweden e-mail: goran.sundkvist@med.lu.se

Tel.: +46-40-331000

Fax: +46-40-336201

G. Stenström

Department of Medicine, Kungsbacka Hospital, Göteborg University, Göteborg, Sweden

P. Fernlund

Clinical Chemistry, Department of Laboratory Medicine Malmö, Lund University, Malmö University Hospital,

Malmö, Sweden

H. J. Arnqvist

Department of Medicine and Care, Linköping University, Linköping, Sweden

A. Ekbom-Schnell

Department of Medicine, Uppsala Academic Hospital,

Uppsala, Sweden

J. Bolinder

Department of Medicine,

Karolinska University Hospital Huddinge, Stockholm, Sweden

J. W. Eriksson - L. Nyström

Department of Medicine, Umeå University Hospital,

Umeå, Sweden

S. Gudbjörnsdottir

Department of Medicine, Sahlgrenska University Hospital,

Göteborg, Sweden for $1,872(90 \%)$ of the 2,077 young adult patients (aged 15-34 years old) over a 5-year period in the nationwide Diabetes Incidence Study in Sweden. Islet antibodies were measured at diagnosis in 1,869 patients, fasting plasma C-peptide (fpC-peptide) after diagnosis in 1,522 , while $H L A-D Q B 1$ genotypes were determined in 1,743. Results: Islet antibodies were found in $83 \%$ of patients clinically considered to have type 1 diabetes, $23 \%$ with type 2 diabetes and $45 \%$ with unclassifiable diabetes. After diagnosis, median $\mathrm{fpC}$-peptide concentrations were markedly lower in patients with islet antibodies than in those without $(0.24$ vs $0.69 \mathrm{nmol} / 1, p<0.0001)$. Irrespective of clinical classification, patients with islet antibodies showed increased frequencies of at least one of the riskassociated $H L A-D Q B 1$ genotypes compared with patients without. Antibody-negative patients with risk-associated $H L A-D Q B 1$ genotypes had significantly lower median fpC-peptide concentrations than those without riskassociated genotypes ( 0.51 vs $0.74 \mathrm{nmol} / 1, p=0.0003)$. Conclusions/interpretation: Assessment of islet antibodies is necessary for the aetiological classification of diabetic patients. $H L A-D Q B 1$ genotyping does not improve the classification in patients with islet antibodies. However, in patients without islet antibodies, $H L A-D Q B 1$ genotyping together with $C$-peptide measurement may be of value in differentiating between idiopathic type 1 diabetes and type 2 diabetes.

Keywords $H L A-D Q B 1$ genotypes · Classification · C-peptide $\cdot$ Islet antibodies

Abbreviations $\mathrm{Ab}+$ : positive for islet antibodies . $\mathrm{Ab}-$ : negative for islet antibodies - DASP: Diabetes Autoantibody Standardization Program - DISS: Diabetes Incidence Study in Sweden - fpC-peptide: fasting plasma C-peptide - GADA: GAD antibodies - IA-2A: protein tyrosine phosphatase-like protein antibodies .

ICA: islet cell antibodies - JDF: Juvenile Diabetes Foundation - OR: odds ratio 


\section{Introduction}

Type 1 and type 2 diabetes are different in terms of aetiology and clinical course. However, if only a clinical assessment is used for diagnosis, it is difficult to distinguish the two main types of diabetes from each other [1-4]. Among patients with the type 2 diabetes phenotype, depending on age at onset, $8-30 \%$ have islet antibodies, indicating that the correct diagnosis would be autoimmune type 1 diabetes [5-7]. Besides autoimmune markers, certain HLA genotypes confer increased risk of type 1 diabetes [8-10]. Compared with islet antibodies and fasting plasma C-peptide (fpC-peptide) concentration as a measure of beta cell function, the value of type 1 diabetes-associated HLA genotypes in the classification of diabetes among young adults has not been established.

The aim of this study was to evaluate the diagnostic value of $H L A-D Q B 1$ genotypes in the classification of diabetes as compared with islet autoantibodies and $\mathrm{fpC}$ peptide among young adults, using a 5-year cohort of incident diabetic patients in the Diabetes Incidence Study in Sweden (DISS).

\section{Subjects and methods}

\section{Subjects}

Over a 5-year period (1 Jan 1998 to 31 December 2002), 2,077 young adult diabetic patients (15-34 years of age) were reported to the DISS. Type of diabetes, age, sex, height, body weight, symptoms at diagnosis, duration of symptoms, date of diagnosis, family history of diabetes and blood glucose values at diagnosis were recorded on a special form by the reporting physician. The patients were invited to donate a blood sample for determination of islet antibodies (islet cell antibodies [ICA], GAD antibodies [GADA], protein tyrosine phosphatase-like protein antibodies [IA-2A]) and $H L A-D Q B 1$ genotypes at diagnosis, and a blood sample for determination of fpC-peptide after diagnosis (median $=4$ months, $Q_{1}=3$ months, $Q_{3}=6$ months). Blood samples were available for $1,872(90 \%)$ of the 2,077 patients. Islet antibodies were measured in 1,869 , fpCpeptide in 1,522 , while $H L A-D Q B 1$ genotypes were determined in 1,743 patients. Figure 1 shows a flow chart of the different assessments conducted.

Using a computer-based patient administrative register as a second source, the level of ascertainment in DISS during 1983-1987 was estimated at 78\% in women and at $79 \%$ in men in the two southernmost counties, covering $9.2 \%$ of the population at risk. For clinical type 1 diabetes the level was $86 \%$ [11]. A similar study in the county of Västerbotten in northern Sweden, covering $2.9 \%$ of the population at risk, found no trend in the level of ascertainment during 1986-1997. The level of ascertainment for clinical type 1 diabetes was $91 \%$. Furthermore, the median level of ascertainment for clinical type 1 diabetes at six diabetic clinics continuously assessed using DIABASE software (Kungälv, Sweden) was $82 \%$ for their patients. Therefore, the ascertainment rate in DISS during the years of study seems to be constant. Level of ascertainment was assessed using the two-sample capture-recapture method [11]. The ethics committee at the Karolinska Institute (Stockholm) approved the study, which was conducted after the patients had given informed consent.
Fig. 1 Flow chart of DISS patients recruited during the 5-year study period (1998-2002 inclusive). The upper part of the figure shows the 2,077 incident cases of young adult diabetic patients (aged 15-34 years) included in the study, with all available collected clinical and biological data. The lower part of the figure shows the 2,018 clinically classified diabetic patients and collected data on $H L A-D Q B 1$ genotypes, islet antibodies and follow-up fpC-peptide

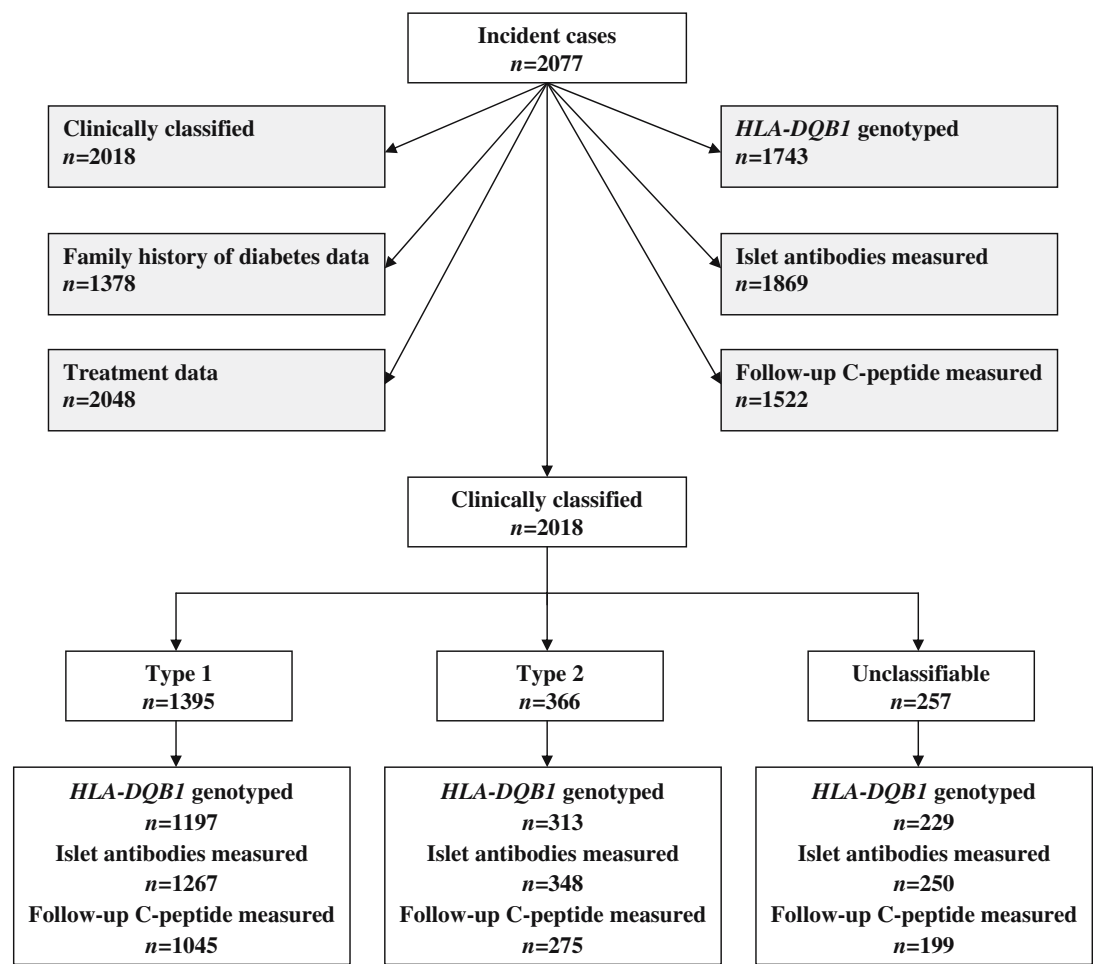


$H L A-D Q B 1$ genotyping

Using a primer pair with biotinylated $3^{\prime}$ primers, the 158-bp second exon of $H L A-D Q B 1$ was amplified by PCR. The amplification product was bound to streptavadin-coated microtitration plates and denatured with $\mathrm{NaOH}$. After washing, bound DNA was assessed using two different hybridisation mixtures with lanthanide (III) chelatelabelled DNA probes specific for the $H L A-D Q B 1$ alleles. One mixture contained europium (Eu)-labelled internal reporter probe for $D Q B 1 * 0602$ and $* 0603$ alleles $(* 0602$ $* 0603)$, samarium (Sm)-labelled probe for *0603 and *0604 alleles (*0603-*0604), and terbium (Tb)-labelled consensus sequence-specific probe (Tb- $D Q B 1$ control) as a control for PCR amplification. The other mixture contained $\mathrm{Tb}-, \mathrm{Sm}$ - and Eu-labelled probes specific for $D Q B 1 * 0201$, $* 0301$ and *0302 alleles, respectively. To measure probe hybridisation, microtitration plates were evaluated by timeresolved fluorescence (Delfia Research Fluorometer; Wallac OY, Turku, Finland). Different emission wavelengths and delay times were used to distinguish the signals of each lanthanide label [12]. Volunteers without diabetes $(n=216)$ from the county of Skaraborg, Sweden were used as control subjects for $H L A-D Q B 1$ genotyping. In control subjects, the $H L A-D Q B 1$ locus was amplified by PCR, followed by dot blotting onto nitrocellulose filters, hybridisation using the radioactively end-labelled sequencespecific oligonucleotide probes, and autoradiography [13].

\section{ICA}

ICA were determined by a prolonged two-colour immunofluorescence assay [14]. The detection limit for ICA was four Juvenile Diabetes Foundation (JDF) units for the first pancreas used in samples tested up to April 1999, and five JDF units for the second pancreas used in samples tested from April 1999 and onwards. In the last ICA Proficiency Test (13th), our ICA assay performed with $100 \%$ sensitivity and $100 \%$ specificity (ICA is not included in the Diabetes Autoantibody Standardization Program [DASP]).

\section{GADA}

GADA were measured by a radioligand binding assay based on human ${ }^{35} \mathrm{~S}$-labelled recombinant GAD65 [15]. The results are presented as an index: GADA index $=100 \times(u-n) /(p-n)$, where $u$ is the cpm (mean activity of all four measurements for a sample) of the unknown sample, $n$ is cpm of the negative control, and $p$ is cpm of the positive control. A GADA index $>4.6$ was considered positive (97.5 percentile of 165 non-diabetic control subjects aged 7-34 years). In the first DASP (in 2000), our GADA assay showed a sensitivity of $80 \%$ and a specificity of $96 \%$; in the second (in 2002), a sensitivity of $88 \%$ and a specificity of $87 \%$; and in the third DASP (in 2003), a sensitivity of $82 \%$ and a specificity of $93 \%$.
IA-2A

IA-2A were measured by an assay similar to that for GADA, which was based on human ${ }^{35} \mathrm{~S}$-labelled recombinant IA-2 [16]. An IA-2A index $>1.0$ was considered positive (97.5 percentile of 165 non-diabetic controls aged 7-34 years). In the first DASP (in 2000), our IA-2A assay showed a sensitivity of $58 \%$ and a specificity of $100 \%$; in the second (in 2002), a sensitivity of $62 \%$ and a specificity of $100 \%$; and in the third DASP (in 2003), a sensitivity of $64 \%$ and a specificity of $100 \%$.

\section{Plasma C-peptide}

A RIA was used to determine fpC-peptide. The detection limit was 0.10 and $0.25-0.75 \mathrm{nmol} / 1$ was considered the normal range. A fpC-peptide concentration $0.1-0.25 \mathrm{nmol} / 1$ was considered low and $<0.10 \mathrm{nmol} / 1$ as immeasurable (beta cell failure) [17].

\section{Clinical classification}

At diagnosis, based on clinical judgment by the reporting physician, the patient was classified as having type 1, type 2 or unclassifiable diabetes.

\section{Statistical analysis}

Comparison of genotype frequencies between diabetic patients and control subjects was tested by two-tailed Fisher's exact test or $\chi^{2}$ test with Bonferroni adjustment $(0.05 / 19$ [number of genotypes in the study]) of $p$ values for multiple comparisons $(p<0.0026$ [0.05/19] was considered significant). Odds ratios (ORs) and $95 \%$ CIs were calculated using the formula $(a \times d) /(b \times c)$, where $a$ is the number of diabetic patients with one of the genotypes, $b$ is the number of control subjects with the corresponding genotype, $c$ is the number of patients without this genotype, and $d$ is the number of control subjects without the corresponding genotype. Differences in continuous variables between groups were assessed by non-parametric Wilcoxon signed-rank test. Regression analysis was used for multiple comparisons. All statistical tests were performed by SPSS (version 11.0; SPSS, Chicago, IL, USA) or JMP (version 5; SAS Institute, Cary, NC, USA) for MAC OS X. In univariate analysis $p<0.05$ was considered significant, whereas in multivariate analysis $p<0.0026$ was considered significant. Continuous data are presented as median and 25th and 75th percentiles $\left(Q_{1}\right.$ and $Q_{3}$ ), and dichotomous data as absolute values and percentage. 


\section{Results}

Of the 2,077 incident diabetic patients, 2,018 were classified by the reporting physicians: 1,395 (69\%) were given a diagnosis of clinical type 1 diabetes, $366(18 \%)$ of clinical type 2 diabetes and $257(13 \%)$ could not be classified (unclassifiable diabetes). There was a clear male preponderance among clinical type 1 diabetic patients (ratio of men:women=1.9) (Table 1). Patients with clinical type 1 diabetes were younger ( 24 vs 30 and 28 years, respectively, $p<0.0001)$ and had a lower BMI (22 vs 32 and 25 , respectively, $p<0.0001$ ) than patients with clinical type 2 or unclassifiable diabetes. A family history of diabetes was more frequent in clinical type $2(53 \%)$ than in clinical type $1(22 \%, p<0.0001)$ or unclassifiable $(38 \%$, $p=0.004$ ) diabetes (Table 1).

Among all patients, 1,250 (67\%) were positive for islet antibodies $(\mathrm{Ab}+)$. The prevalence of islet antibodies was significantly higher in clinical type 1 diabetic patients than in unclassifiable patients ( 83 vs $45 \%, p<0.0001$ ), who, in turn, showed a higher prevalence of islet antibodies than patients with clinical type 2 diabetes (45 vs $23 \%$, $p<0.0001)$. Irrespective of the clinical classification, almost half of $\mathrm{Ab}+$ individuals had three different antibodies. Among patients positive for ICA, the median ICA titre was significantly higher in patients with clinical type 1 diabetes than in patients with unclassifiable diabetes $\left(58\left[Q_{1}=26\right.\right.$, $\left.Q_{3}=130\right]$ vs $45\left[Q_{1}=17, Q_{3}=87\right] \mathrm{JDF}$ units, respectively,

Table 1 Characteristics of 2,018 patients in DISS (1998-2002 inclusive) according to clinical classification as provided by the patients to DISS reporting physicians

\begin{tabular}{|c|c|c|c|c|c|}
\hline & \multirow{2}{*}{$\begin{array}{l}\text { Incident cases } \\
(n=2,077)\end{array}$} & \multicolumn{3}{|c|}{ Clinical type of diabetes ${ }^{\mathrm{a}}$} & \multirow[t]{2}{*}{$p$ value } \\
\hline & & $\begin{array}{l}\text { Type } 1 \\
(n=1,395)\end{array}$ & $\begin{array}{l}\text { Type } 2 \\
(n=366)\end{array}$ & $\begin{array}{l}\text { Unclassifiable } \\
(n=257)\end{array}$ & \\
\hline Sex, ratio of men:women & 1.6 & 1.9 & 1.3 & 1.0 & $<0.0001$ \\
\hline Age at onset (years), median $\left(Q_{1}, Q_{3}\right)$ & $26(20,30)$ & $24(19,29)^{\mathrm{b}}$ & $30(26,32)^{\mathrm{c}}$ & $28(24,32)$ & $<0.0001$ \\
\hline BMI $\left(\mathrm{kg} / \mathrm{m}^{2}\right)$, median $\left(Q_{1}, Q_{3}\right)$ & $23(21,27)$ & $22(20,24)^{\mathrm{d}}$ & $32(27,37)$ & $25(22,30)$ & $<0.0001$ \\
\hline \multicolumn{6}{|l|}{ Family history of diabetes ${ }^{\mathrm{e}}$} \\
\hline Yes & $407(30)$ & $211(22)^{b}$ & $130(53)^{\mathrm{f}}$ & $66(38)$ & \multirow[t]{2}{*}{$<0.0001$} \\
\hline No & $971(70)$ & $746(78)$ & $116(47)$ & $107(62)$ & \\
\hline \multicolumn{6}{|l|}{ Treatment regimen ${ }^{\mathrm{g}}$} \\
\hline Insulin & $1694(83)$ & $1339(97)^{\mathrm{d}}$ & $142(39)$ & $169(66)$ & \multirow[t]{2}{*}{$<0.0001$} \\
\hline No insulin & 354 (17) & $40(2.9)$ & $221(61)$ & $86(34)$ & \\
\hline Patients with antibodies $(\mathrm{Ab}+)^{\mathrm{h}}$ & $1250(67)$ & $1056(83)^{d}$ & $79(23)$ & $113(45)$ & \multirow[t]{2}{*}{$<0.0001$} \\
\hline Patients without antibodies $\left(\mathrm{Ab}^{-}\right)$ & $619(33)$ & $211(17)$ & $269(77)$ & $137(55)$ & \\
\hline \multicolumn{6}{|l|}{$\begin{array}{l}\text { No. of antibodies detected among those } \mathrm{Ab}+ \\
\text { All three } \mathrm{Ab}+\end{array}$} \\
\hline $\mathrm{ICA}+\mathrm{GADA}+\mathrm{IA}-2 \mathrm{~A}$ & $591(47)$ & $504(48)$ & $32(41)$ & $55(49)$ & \\
\hline \multicolumn{6}{|l|}{ Two $\mathrm{Ab}+$} \\
\hline $\mathrm{ICA}+\mathrm{GADA}$ & $216(17)$ & $180(17)$ & $16(20)$ & $19(17)$ & \\
\hline $\mathrm{ICA}+\mathrm{IA}-2 \mathrm{~A}$ & $76(6.1)$ & $69(6.5)$ & $5(6.3)$ & $1(0.9)$ & \\
\hline GADA+IA-2A & $78(6.2)$ & $68(6.4)$ & $6(7.6)$ & $4(3.5)$ & 0.36 \\
\hline \multicolumn{6}{|l|}{ One $\mathrm{Ab}+$} \\
\hline ICA & $32(2.6)$ & $26(2.5)$ & $3(3.8)$ & $3(2.7)$ & \\
\hline GADA & $226(18)$ & $186(18)$ & $14(18)$ & $26(23)$ & \\
\hline IA-2A & $31(2.5)$ & $23(2.2)$ & $3(3.8)$ & $5(4.4)$ & \\
\hline \multicolumn{6}{|l|}{ Antibody levels } \\
\hline $\mathrm{ICA}+$, median $\left(Q_{1}, Q_{3}\right)$ & $58(26,130)$ & $58(26,130)^{\mathrm{i}}$ & $58(26,130)$ & $45(17,87)$ & 0.03 \\
\hline GADA + , median $\left(Q_{1}, Q_{3}\right)$ & $54(20,103)$ & $51(19,102)$ & $65(17,110)$ & $65(29,101)$ & 0.16 \\
\hline $\mathrm{IA}-2 \mathrm{~A}+$, median $\left(Q_{1}, Q_{3}\right)$ & $92(30,115)$ & $95(36,115)^{\mathrm{j}}$ & $87(15,115)$ & $51(7,114)$ & 0.04 \\
\hline Follow-up fpC-peptide ${ }^{\mathrm{k}}$, median $\left(Q_{1}, Q_{3}\right)$ & $0.31(0.17,0.59)$ & $0.24(0.14,0.40)^{\mathrm{d}}$ & $0.74(0.48,1.14)$ & $0.48(0.26,0.84)$ & $<0.0001$ \\
\hline
\end{tabular}

Data are presented as absolute numbers $(\%)$ or median, 25th percentile $\left(Q_{1}\right)$, and 75 th percentile $\left(Q_{3}\right)$. The $\chi^{2} p$ values for comparison between three groups (type 1 , type 2 and unclassifiable) are shown. Using a computer-based patient administrative register as a second source, the level of ascertainment in DISS during 1983-1987 was estimated at 78\% in women and at 79\% in men in the two southernmost counties, covering $9.2 \%$ of the population at risk. ${ }^{\text {a }}$ There were 2,018 clinically classified patients; ${ }^{\mathrm{b}} p<0.0001$ for type 1 vs type 2 and type 1 vs unclassifiable; ${ }^{\mathrm{c}} p=0.002$ for type 2 vs unclassifiable; ${ }^{\mathrm{d}} p<0.0001$ for type 1 vs type 2 , type 1 vs unclassifiable, and unclassifiable vs type $2 ;{ }^{\mathrm{e}} 1,378$ patients had information regarding possible family history of diabetes; ${ }^{\mathrm{f}} p=0.004$ for type 2 vs unclassifiable; ${ }^{\mathrm{g}} 2,048$ patients had information regarding treatment; ${ }^{\mathrm{h}} 1,869$ patients had islet antibodies; ${ }^{\mathrm{i}} p=0.008$ for type $1 \mathrm{vs}$ unclassifiable; ${ }^{\mathrm{j}} p=0.01$ for type $1 \mathrm{vs}$ unclassifiable; ${ }^{\mathrm{k}} 1522$ patients had measured follow-up fpC-peptide; follow-up C-peptide was measured at $\leq 6$ months after diagnosis in 1,522 patients and $>6$ months in 370 patients 


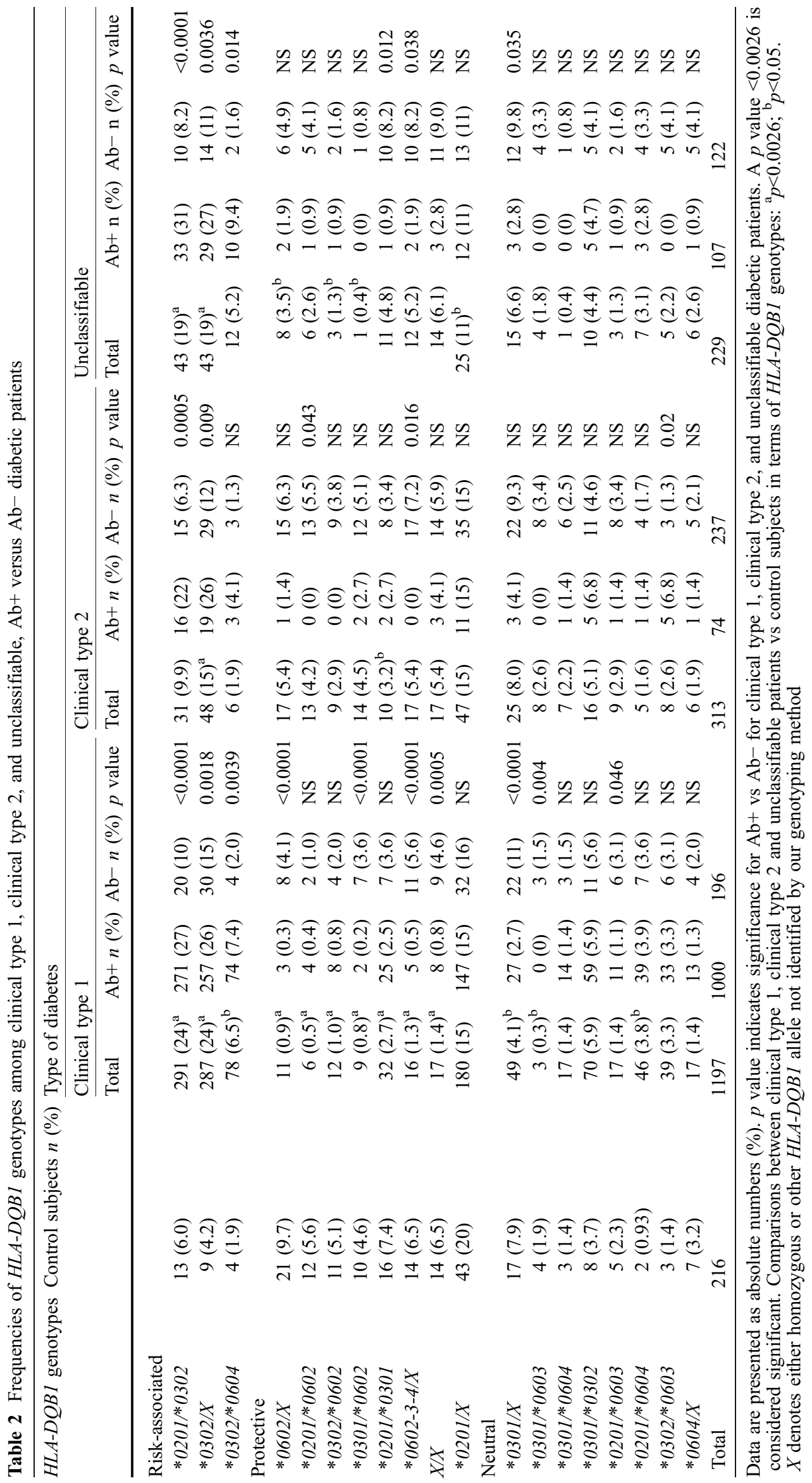


$p=0.008)$. Similarly, among IA-2A-positive patients, the median IA-2A titre was significantly higher in type 1 diabetic patients than in those with unclassifiable diabetes (index values $95\left[Q_{1}=36, Q_{3}=115\right]$ vs $51\left[Q_{1}=7, Q_{3}=114\right]$, respectively, $p=0.01$ ) compared with those with unclassifiable diabetes. Similar differences were not seen for GADA.

\section{$H L A-D Q B 1$ genotypes}

Table 2 shows that, irrespective of their clinical classification, $\mathrm{Ab}+$ patients had a significantly higher prevalence of risk-associated $H L A-D Q B 1$ genotypes. However, among clinical type 1 diabetic patients, some protective and neutral $H L A-D Q B 1$ genotypes were significantly more frequent among those who were $\mathrm{Ab}-$ than those who were $\mathrm{Ab}+$.

Patients with a young age at onset of diabetes ( $\leq 25$ years) had a two-fold increased risk of having the $H L A-D Q B 1 * 0201 * 0302$ genotype $(\mathrm{OR}=1.6,95 \%$ CI $1.3-2.1, p<0.0001)$ relative to those with an older age at onset ( $>25$ years); however, this effect disappeared in multivariate analysis when islet antibodies were included. In this analysis, age at onset was included as a dependent categorical, and $H L A-D Q B 1$ genotypes and islet antibodies were included as independent categorical variables.

Islet antibodies in relation to $H L A-D Q B 1$ genotypes, age at onset and sex

Patients with the $H L A-D Q B 1 * 0201 / * 0302$ genotype had a three-fold increased risk of having GADA (OR=3.4, 95\% CI $2.4-4.7, p<0.0001)$ relative to patients with protective/ neutral genotypes. In contrast, patients with HLA-
$D Q B 1^{*} 0302 / X$ (where $X$ denotes either homozygous or other $H L A-D Q B 1$ allele not identified by our genotyping method) had a three-fold increased risk of having IA-2A $(\mathrm{OR}=3.2,95 \% \mathrm{CI} 2.3-4.4, p<0.0001)$ relative to patients with protective/neutral genotypes, and in patients with $H L A-D Q B 1 * 0302 / * 0604$, the risk was increased five-fold $(\mathrm{OR}=5.6,95 \%$ CI $3.1-10.2, p<0.0001)$ than patients with protective/neutral genotypes.

Being $\mathrm{Ab}+$ was significantly associated with young age at onset of diabetes ( $\leq 25$ years) as compared with $\mathrm{Ab}-(654$ [52\%] vs 180 [29\%], $p<0.0001)$. Age at onset and sex (independent categorical variables) in relation to different islet antibody combinations (dependent categorical variable) included in a multinomial logistic regression analysis showed that young age at onset $(\leq 25$ years) was independently and significantly $(p<0.0001)$ associated with islet antibodies, particularly with IA-2A, alone $(\mathrm{OR}=7.2,95 \%$ CI $3.2-16.4, p<0.0001)$ or in combination with ICA $(\mathrm{OR}=7.0,95 \%$ CI 4.1-12.0, $p<0.0001)$. In addition, male sex was independently associated with IA-2A, alone $(\mathrm{OR}=5.7 ; 95 \%$ CI $1.7-18.9, p=0.005)$ or in combination with ICA (OR=4.0; 95\% CI 2.0-8.0, $p<0.0001$ ), whereas female sex was independently associated with GADA in combination with ICA $(\mathrm{OR}=1.7$, 95\% CI 1.3-2.4, $p=0.001)$. Among patients positive for GADA, the median GADA concentration was significantly higher in women than in men (index values $82\left[Q_{1}=27\right.$, $\left.Q_{3}=112\right]$ vs $\left.39\left[Q_{1}=16, Q_{3}=91\right], p<0.0001\right)$.

fpC-peptide in relation to islet antibodies and $H L A-D Q B 1$ genotypes

Table 1 shows that the median fpC-peptide concentration after diagnosis was significantly $(p<0.0001)$ lower among

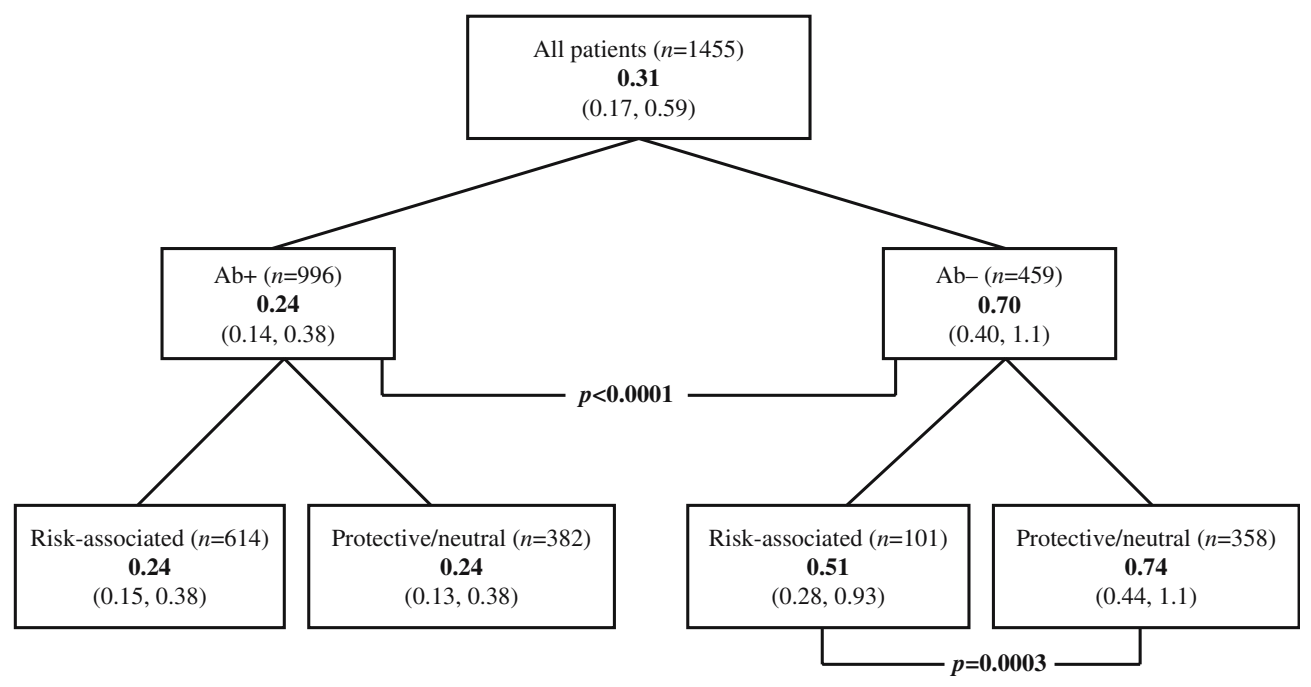

Fig. 2 Levels of fpC-peptide measured at follow-up in relation to islet antibodies and $H L A-D Q B 1$ genotypes. Altogether, complete data on follow-up fpC-peptide, HLA-DQB1 genotypes and islet antibodies were available for 1,455 patients. The figure shows median fpC-peptide concentrations in bold (nmol/1), and 25th percentile $\left(Q_{1}\right)$ and 75 th percentile $\left(Q_{3}\right)$ values in brackets. The

median fpC-peptide concentration was significantly $(p<0.0001)$ lower in $\mathrm{Ab}+$ vs $\mathrm{Ab}-$ patients, irrespective of $H L A-D Q B 1$ genotypes. However, $\mathrm{Ab}^{-}$patients with risk-associated $H L A$ $D Q B 1$ genotypes had significantly lower $(p=0003)$ median $\mathrm{fpC}$ peptide levels than $\mathrm{Ab}$ - patients with protective/neutral genotypes 
patients with clinical type 1 diabetes $(0.24 \mathrm{nmol} / \mathrm{l})$ than among those with clinical type 2 diabetes $(0.75 \mathrm{nmol} / \mathrm{l})$ or unclassifiable $(0.48 \mathrm{nmol} / \mathrm{l})$ diabetes. Figure 2 shows that $\mathrm{Ab}+$ patients had a significantly lower median fpC-peptide concentration than $\mathrm{Ab}-$ patients $(0.24$ vs $0.70 \mathrm{nmol} / \mathrm{l}$, $p<0.0001$ ), irrespective of the presence of risk-associated $H L A-D Q B 1$ genotypes or not. On the other hand, $\mathrm{Ab}-$ patients with risk-associated $H L A-D Q B 1$ genotypes had a significantly lower median fpC-peptide concentration than patients with protective/neutral genotypes ( 0.51 vs $0.74 \mathrm{nmol} / 1, p=0.0003)$. After stratification for islet antibody presence, multiple regression analysis was performed in each group $\left(\mathrm{Ab}+\right.$ and $\left.\mathrm{Ab}^{-}\right)$. This analysis included fpC-peptide (dependent continuous variable), fpC-peptide follow-up time ( $\leq 6$ months or $>6$ months) and HLA-DQBI genotypes (independent categorical variables). The analysis showed that among $\mathrm{Ab}-$ patients, risk-associated $H L A$ $D Q B 1$ genotypes were significantly $(p=0.001)$ associated with decreased fpC-peptide concentration, irrespective of when the follow-up sample was taken. In contrast, among $\mathrm{Ab}+$ patients, a long fpC-peptide follow-up time ( $>6$ months) was significantly $(p<0.0001)$ associated with decreased fpC-peptide concentration, irrespective of riskassociated $H L A-D Q B 1$ genotypes.

Categorisation of fpC-peptide according to low $(\leq 0.25 \mathrm{nmol} / \mathrm{l})$ or normal $(>0.25 \mathrm{nmol} / \mathrm{l})$ concentrations, respectively, showed that a low fpC-peptide $(\leq 0.25 \mathrm{nmol} / \mathrm{l})$ concentration was significantly associated with islet antibodies $(p<0.0001)$ but not with $H L A-D Q B 1$ genotypes in multinomial logistic regression analysis. In the regression analysis, nominal fpC-peptide was included as a dependent categorical variable and islet antibodies, $H L A$ $D Q B 1$ genotypes, follow-up time, age at onset, sex, BMI and family history of diabetes as independent categorical variables.

Ketonuria, acidosis, diabetic symptoms in relation to islet $H L A-D Q B 1$ genotypes, islet antibodies, fpC-peptide, age at onset and sex

At diagnosis, 1,138 (60\%) of diabetic patients had ketonuria, $149(10 \%)$ had acidosis and 1,835 (93\%) had diabetic symptoms; 1,401 (75\%) had a short duration of diabetic symptoms ( $<3$ months). Multinomial regression analysis showed that presence of ketonuria was significantly $(p<0.0001)$ associated with islet antibodies, particularly ICA combined with IA-2A $(\mathrm{OR}=4.0,95 \%$ CI 1.9-8.1) or three antibodies (OR=3.2, 95\% CI 2.34.6) or male sex $(\mathrm{OR}=1.8,95 \%$ CI 1.4-2.3), but not with risk-associated $H L A-D Q B 1$ genotypes. Prevalence of diabetic symptoms was significantly $(p<0.0001)$ associated with three antibodies $(\mathrm{OR}=4.3,95 \% \mathrm{CI} 2.0-9.1)$ and male sex $(\mathrm{OR}=2.5 ; 95 \%$ CI 1.5-4.0). Moreover, short length of symptomatic period ( $<3$ months) was significantly associated $(p<0.0001)$ with three antibodies $(\mathrm{OR}=2.4 ; 95 \% \mathrm{CI}$ 1.6-3.6). In the regression analysis, presence of ketonuria, the prevalence of diabetic symptoms and length of symptomatic period were separately included as dependent categorical variables, whereas islet antibodies, $H L A-D Q B 1$ genotypes, fpC-peptide, follow-up time, sex, age at onset, BMI and family history of diabetes were included as independent categorical variables.

\section{Discussion}

This study of 2,077 young adults (15-34 years old) with recently diagnosed diabetes, 1,869 of whom had islet antibodies measured, shows that 1,250 of $1,869(67 \%)$ had autoimmune type 1 diabetes if islet antibodies were used as an objective diagnosis of autoimmune type 1 diabetes. Among those classified as having type 1 diabetes, $83 \%$ had objective type 1 diabetes; however, $23 \%$ of those classified with type 2 diabetes and $45 \%$ of those classified with unclassifiable diabetes also had objective type 1 diabetes. If immeasurable or low fpC-peptide after diagnosis was included as a further objective criterion for clinical type 1 diabetes, only another 70 patients without islet antibodies were added to the clinical type 1 diabetes group. Hence, if patients with low or immeasurable fpC-peptide were to be included, the proportion with type 1 diabetes would increase by only $4 \%$, i.e. $71 \%$ of all incident young adults between 15 and 34 years of age developing diabetes would have objective type 1 diabetes. Accordingly, islet antibodies, not fpC-peptide, are most important in the classification of diabetes among young adults. Nevertheless, our study has shown that non-autoimmune diabetes (presumably mostly type 2 diabetes) is not rare among young adult diabetic patients, being identified in about every third patient. Hence, the differential diagnosis between clinical type 1 and clinical type 2 diabetes is a major issue among incident diabetic patients aged 15-34 years.

Based on islet antibodies at diagnosis, we have previously reported that around $25 \%$ of clinical type 2 , and $50 \%$ of unclassifiable young adult diabetic patients, should be considered as having type 1 diabetes $[1,18]$. It is noteworthy that the current DISS study, conducted from the start of 1998 to the end of 2002, gives similar frequencies of islet antibodies among clinical type 2 and unclassifiable diabetic patients, as shown in the previous DISS studies performed in 1987-1988 and 1992-1993. This highlights the fact that, among those aged 15-34 years, an objective classification based on islet antibodies is necessary to achieve a reliable classification.

Our study emphasises that, although risk-associated $H L A-D Q B 1$ genotypes are closely associated with islet antibodies, these $H L A-D Q B 1$ genotypes do not contribute to the classification of type 1 diabetes per se. Indeed, the only suggestion that risk-associated $H L A-D Q B 1$ genotypes may contribute to an aetiological classification was among patients without islet antibodies. In line with the Belgian Diabetes Registry [3], we found that among $\mathrm{Ab}$ individuals, those with risk-associated $H L A-D Q B 1$ genotypes had a lower median fpC-peptide concentration than those with protective/neutral genotypes, irrespective of the timing of the follow-up fpC-peptide measurement. However, patients with islet antibodies and samples taken 
6 months after diagnosis had low fpC-peptide concentrations, irrespective of risk-associated $H L A-D Q B 1$ genotypes, again underlining that in the presence of islet antibodies, genetic risk assessment based on HLA is not important in the classification. It was also observed previously that in the presence of islet antibodies, genetic risk or protection does not matter in the prediction of diabetes development [19-21]. Our observation that low fpC-peptide was associated with risk-associated HLA genotypes in $\mathrm{Ab}$ - participants indicates that risk-associated $H L A-D Q B 1$ genotypes may themselves be related to impaired beta cell function. This corresponds to previous reports that the presence of a risk-associated genotype in $\mathrm{Ab}-$ patients confers an increased risk of insulin requirement at a later follow-up [22]. However, antibodies not detected by current assays may be present in patients without islet antibodies but with risk-associated $H L A$ $D Q B 1$ genotypes and low fpC-peptide. Another option is a later development of islet antibodies. Previous studies have shown that up to $10 \%$ of young adult-onset diabetic patients without islet antibodies convert to positivity after the diagnosis of diabetes [23-26]. The disappearance of previous islet antibodies should also be considered.

Interesting associations between risk-associated $H L A$ $D Q B 1$ genotypes, age at onset of diabetes and islet antibodies were detected. It has been reported that diabetic patients with a young age at onset ( $\leq 25$ years) have increased frequencies of $H L A-D Q B 1 * 0201 / 0302$ genotypes [27-30]; however, according to our study, significant associations between $H L A-D Q B 1$ genotypes and young age at onset were due to islet antibodies. In agreement with previous observations [31-33], GADA were associated with $H L A-D Q B 1 * 0201 * 0302$, whereas IA-2A were associated with $H L A-D Q B 1 * 0302 / X$ and $* 0302 / * 0604$, respectively. Indeed, IA-2A concentration was highest among patients with the $H L A-D Q B 1 * 0302 / X$ genotype. IA-2A are known to be associated with a rapid onset of type 1 diabetes, as well as with young age at onset [34-36]. Hence, our study infers that the association between IA-2A and rapid onset may be dependent on the HLA-DQB1 locus. Our study also confirms that IA-2A were associated with male sex, whereas the presence and high levels of GADA were associated with female sex [37, 38]. However, logistic regression analysis showed that the associations between sex and age at onset to the types of islet antibodies were not related to risk-associated $H L A-D Q B 1$ genotypes, as has been previously shown [39]. Thus, the well known increased incidence of type 1 diabetes among young adult men [40-43], as also demonstrated in our study, does not seem to be related to $H L A-D Q B 1$, but an effect of sex in itself. This is emphasised by our finding that ketonuria and diabetic symptoms were clearly associated with male sex.

A clear finding in our study was that normal fpC-peptide up to 6 months after diagnosis does not exclude type 1 diabetes. This finding gives further support to the concept that islet antibodies are the method of choice in the classification of diabetes. The preserved beta cell function in most patients with islet antibodies demonstrates that the process of beta cell destruction is not always fast among young adult diabetic patients. Indeed, it fits with the previous observation that it may take 12 years before severe beta cell failure develops in adult patients with islet antibodies [44].

It has been reported, that high concentrations of islet antibodies are associated with low fpC-peptide values [45], but no such association was shown in our study. We found no correlation between the number of islet antibodies and fpC-peptide, as previously reported [46, 47]. This most likely reflects that beta cell failure was not yet frequent among our study patients. Prospective follow-ups may in the future show high concentrations and/or a high number of islet antibodies in association with beta cell failure among our patients.

The major strength of this study is that we recruited a large sample of incident population-based and representative diabetic patients aged 15-34 years from a whole country. Indeed, since 1983 DISS have included $>9,000$ 15-34-year-old patients at diagnosis of diabetes. In this 5-year study conducted between the start of 1998 and the end of 2002, blood samples were taken in most incident cases and we were able to compare complete data on HLA$D Q B 1$ genotypes, islet antibodies and fpC-peptide in 1,455 newly diagnosed young adult diabetic patients (Fig. 2). It can be argued that we did not determine HLA-DQA1 genotypes in our patients. No doubt that extended genotyping is helpful for relative risk estimation. The sensitivity increases when new genotypes conferring risk are included. However, the linkage disequilibrium between alpha and beta chain alleles is very strong. Additional information obtained by typing for $H L A-D Q A 1$ would thus be of limited importance for our study [12]. Furthermore, our association study of $H L A-D Q B 1$ loci may be considered a cost-effective way of identifying the contribution of $H L A$ to the classification of diabetes in individuals aged $15-34$ years.

In conclusion, this study shows that (1) irrespective of clinical classification, $67 \%$ of patients with newly diagnosed diabetes at the age of 15-34 years have autoimmune type 1 diabetes; (2) islet antibodies strongly contribute to the aetiological classification of diabetes; (3) islet antibodies are more closely associated with beta cell impairment than increased-risk $H L A-D Q B 1$ genotypes; (4) risk-associated $H L A-D Q B 1$ genotypes are associated with islet antibodies and do not contribute to the classification of diabetes in $\mathrm{Ab}+$ individuals; (5) risk-associated $H L A-D Q B 1$ genotypes are, however, associated with low fpC-peptide concentrations in the absence of islet antibodies, presumably identifying non-autoimmune type 1 diabetes; and (6) absence of islet antibodies and high fpC-peptide concentrations predict a type 2 diabetes phenotype. Taken together, the data re-emphasise the need to measure islet antibodies for the diagnosis of autoimmune diabetes in young adults in clinical practice, whereas $H L A-D Q B 1$ genotyping may be of interest in patients without islet antibodies. 
Acknowledgement We thank all Swedish diabetologists and diabetes nurses who contributed to DISS. C. Rosborn, U. Gustavsson, A. Radelius, G. Gremsperger and J. Pilz are acknowledged for expert technical assistance. The Juvenile Diabetes FoundationWallenberg Diabetes Research Program (K 98-99 JD- 128 13), the Swedish Diabetes Association, the Swedish Medical Research Council (72X-14531), the Albert Påhlsson Foundation and the Research Fund at Malmö University Hospital are acknowledged for support of DISS.

Duality of interest L. C. Groop has been a consultant and served on advisory boards for Aventis-Sanofi, Bristol-Myers Squibb, Kowa and Roche.

\section{References}

1. Landin-Olsson M, Karlsson FA, Lernmark $\AA$, Sundkvist G; Diabetes Incidence Study in Sweden Group (1992) Islet cell and thyrogastric antibodies in 633 consecutive 15-34 yr-old patients in the Diabetes Incidence Study in Sweden. Diabetes 41:1022-1027

2. Tuomi T, Carlsson A, Li H et al (1999) Clinical and genetic characteristics of type 2 diabetes with and without GAD antibodies. Diabetes 48:150-157

3. Weets I, Siraux V, Daubresse JC et al (2002) Relation between disease phenotype and HLA-DQ genotype in diabetic patients diagnosed in early adulthood. J Clin Endocrinol Metab 87:2597-2605

4. Arnqvist HJ, Littorin B, Nyström L et al (1993) Difficulties in classifying diabetes at presentation in the young adult. Diabet Med 10:606-613

5. Wroblewski $M$, Gottsäter $A$, Lindgärde $F$, Fernlund $P$, Sundkvist G (1998) Gender, autoantibodies, and obesity in newly diagnosed diabetic patients aged $40-75$ years. Diabetes Care 21:250-255

6. Turner R, Stratton I, Horton V et al (1997) UKPDS 25: autoantibodies to islet-cell cytoplasm and glutamic acid decarboxylase for prediction of insulin requirement in type 2 diabetes. Lancet 350:1288-1293

7. Littorin B, Sundkvist G, Hagopian W et al (1999) Islet cell and glutamic acid decarboxylase antibodies present at diagnosis of diabetes predict the need for insulin treatment. A cohort study in young adults whose disease was initially labeled as type 2 or unclassifiable diabetes. Diabetes Care 22:409-412

8. Nerup J, Platz P, Anderson OO et al (1974) HLA antigens and diabetes mellitus. Lancet ii:864-866

9. Todd JA, Bell JI, McDevitt HO (1987) HLA-DQ beta gene contributes to susceptibility and resistance to insulin-dependent diabetes mellitus. Nature 329:599-604

10. Thorsby E, Ronningen KS (1993) Particular HLA-DQ molecules play a dominant role in determining susceptibility or resistance to type 1 (insulin-dependent) diabetes mellitus. Diabetologia 36:371-377

11. Littorin B, Sundkvist G, Scherstén B et al (1996) Patient administrative system as a tool to validate the ascertainment in the diabetes incidence study in Sweden (DISS). Diabetes Res Clin Pract 33:129-133

12. Ilonen J, Reijonen H, Herva E et al (1996) Rapid HLA-DQB1 genotyping for four alleles in the assessment of risk for IDDM in the Finnish population. The Childhood Diabetes in Finland (DiMe) Study Group. Diabetes Care 19:795-800

13. Stenström G, Berger B, Borg H, Fernlund P, Dorman JS, Sundkvist G (2002) HLA-DQ genotypes in classical type 1 diabetes and in latent autoimmune diabetes of the adult. Am J Epidemiol 156:787-796
14. Landin-Olsson M, Sundkvist G, Lernmark Å (1987) Prolonged incubation in the two-colour immunofluorescence test increases the prevalence and titres of islet cell antibodies in Type 1 (insulin-dependent) diabetes mellitus. Diabetologia 30:327-332

15. Borg H, Fernlund P, Sundkvist G (1997) Measurement of antibodies against glutamic acid decarboxylase (GADA): two new ${ }^{125} \mathrm{I}$ assays compared with $\left[{ }^{35} \mathrm{~S}\right] \mathrm{GAD}$ 65-ligand binding assay. Clin Chem 43:779-785

16. Borg H, Fernlund P, Sundkvist G (1997) Protein tyrosine phosphatase IA2-antibodies plus glutamic acid decarboxylase 65 antibodies (GADA) indicates autoimmunity as frequently as islet cell antibodies assay in children with recently diagnosed diabetes mellitus. Clin Chem 43:2358-2363

17. Gottsäter A, Landin-Olsson M, Fernlund P, Gullberg B, Lernmark A, Sundkvist G (1992) Pancreatic beta-cell function evaluated by intravenous glucose and glucagon stimulation. A comparison between insulin and C-peptide to measure insulin secretion. Scand J Lab Invest 52:631-639

18. Törn C, Landin-Olsson M, Östman J et al (2000) Glutamic acid decarboxylase antibodies (GADA) is the most important factor for prediction of insulin therapy within 3 years in young adult diabetic patients not classified as Type 1 diabetes on clinical grounds. Diabetes Metab Res Rev 16:442-447

19. Greenbaum CJ, Schatz DA, Cuthbertson D, Zeidler A, Eisenbarth GS, Krischer JP (2000) Islet cell antibody-positive relatives with human leukocyte antigen DQA1*0102, DQB1*0602: identification by the Diabetes Prevention Trial-type 1. J Clin Endocrinol Metab 85:1255-1260

20. LaGasse JM, Brantley MS, Leech NJ et al (2002) Successful prospective prediction of type 1 diabetes in schoolchildren through multiple defined autoantibodies: an 8-year follow-up of the Washington State Diabetes Prediction Study. Diabetes Care 25:505-511

21. Redondo MJ, Babu S, Zeidler A et al (2006) Specific HLA DQ influence on expression of anti-islet autoantibodies and progression to type 1 diabetes. J Clin Endocrinol Metab 91:1705-1713

22. Pietropaolo M, Becker DJ, LaPorte RE et al (2002) Progression to insulin-requiring diabetes in seronegative prediabetic subjects: the role of two HLA-DQ high-risk haplotypes. Diabetologia 45:66-76

23. Sundkvist G, Hagopian WA, Landin-Olsson M et al (1994) Islet cell antibodies (ICA), but not glutamic acid decarboxylase antibodies (GAD65-Ab), are decreased by plasmapheresis in patients with newly diagnosed insulin-dependent diabetes mellitus. J Clin Endocrinol Metab 78:1159-1165

24. Landin-Olsson M, Arnqvist HJ, Blohmé G et al (1999) Appearance of islet cell autoantibodies after clinical diagnosis of diabetes mellitus. Autoimmunity 29:57-63

25. Decochez K, Tits J, Coolens JL et al (2000) High frequency of persisting or increasing islet-specific autoantibody levels after diagnosis of type 1 diabetes presenting before 40 years of age. The Belgian Diabetes Registry. Diabetes Care 23:838-844

26. Borg H, Arnqvist HJ, Bjork E et al (2003) Evaluation of the new ADA and WHO criteria for classification of diabetes mellitus in young adult people (15-34 yrs) in the Diabetes Incidence Study in Sweden (DISS). Diabetologia 46:173-181

27. Caillat-Zucman S, Garchon H-J, Timsit J et al (1992) Agedependent HLA genetic heterogeneity of Type 1 insulindependent diabetes mellitus. J Clin Invest 90:2242-2250

28. Tait BD, Harrison LC, Drummond BP, Stewart V, Varney MD, Honeyman MC (1995) HLA antigens and age at diagnosis of insulin-dependent diabetes mellitus. Hum Immunol 42:116-122

29. Valdes AM, Thomson G, Erlich HA, Noble JA (1999) Association between type 1 diabetes age of onset and HLA among sibling pairs. Diabetes 48:1658-1661

30. Emery LM, Babu S, Bugawan TL et al (2005) Newborn HLA-DR,DQ genotype screening: age- and ethnicity-specific type 1 diabetes risk estimates. Pediatr Diabetes 6:136-144 
31. Hagopian WA, Sanjeevi CB, Kockum I et al (1995) Glutamate decarboxylase-, insulin- and islet cell-antibodies and HLA typing to detect diabetes in a general population-based study of Swedish children. J Clin Invest 95:1505-1511

32. Graham J, Hagopian WA, Kockum I et al (2002) Genetic effects on age-dependent onset and islet cell autoantibody markers in type 1 diabetes. Diabetes 51:1346-1355

33. Genovese S, Bonfanti R, Bazzigaluppi E et al (1996) Association of IA-2 autoantibodies with HLA DR4 phenotypes in IDDM. Diabetologia 39:1223-1226

34. Savola K, Bonifacio E, Sabbah E et al (1998) IA-2 antibodiesa sensitive marker of IDDM with clinical onset in childhood and adolescence. Childhood Diabetes in Finland Study Group. Diabetologia 41:424-429

35. Bottazzo GF, Bosi E, Cull CA et al (2005) IA-2 antibody prevalence and risk assessment of early insulin requirement in subjects presenting with type 2 diabetes (UKPDS 71). Diabetologia 48:703-708

36. Gorus FK, Goubert P, Semakula C et al (1997) IA-2autoantibodies complement GAD65-autoantibodies in newonset IDDM patients and help predict impending diabetes in their siblings. Diabetologia 40:95-99

37. Verge CF, Howard NJ, Rowley MJ et al (1994) Anti-glutamate decarboxylase and other antibodies at the onset of childhood IDDM: a population-based study. Diabetologia 37:1113-1120

38. Sabbah E, Kulmala P, Veijola R et al (1996) Glutamic acid decarboxylase antibodies in relation to other autoantibodies and genetic risk markers in children with newly diagnosed insulindependent diabetes. J Clin Endocrinol Metab 81:2455-2459

39. Weets I, Van Autreve J, Van der Auwera BJ et al (2001) Maleto-female excess in diabetes diagnosed in early adulthood is not specific for the immune-mediated form nor is it HLA-DQ restricted: possible relation to increased body mass index. Diabetologia 44:40-47
40. Blohmé G, Nyström L, Arnqvist HJ et al (1992) Male predominance of Type 1 (insulin-dependent) diabetes mellitus in young adults: results from a 5-year prospective nationwide study of the 15-34 year age group in Sweden. Diabetologia $35: 56-62$

41. Vandewalle CL, Coeckelberghs MI, Leeuw IH et al (1997) Epidemiology, clinical aspects, and biology of IDDM patients under age 40 years. Diabetes Care 20:1556-1561

42. Gale EA, Gillespie KM (2001) Diabetes and gender. Diabetologia 44:3-15

43. Kyvik KO, Nystrom L, Gorus F et al (2004) The epidemiology of Type 1 diabetes mellitus is not the same in young adults as in children. Diabetologia 47:377-384

44. Borg H, Gottsater A, Fernlund P, Sundkvist G (2002) A 12-year prospective study of the relationship between islet antibodies and beta-cell function at and after the diagnosis in patients with adult-onset diabetes. Diabetes 51:1754-1762

45. Borg H, Gottsater A, Landin-Olsson M, Fernlund P, Sundkvist G (2001) High levels of antigen-specific islet antibodies predict future beta-cell failure in patients with onset of diabetes in adult age. J Clin Endocrinol Metab 86:3032-3038

46. Schölin A, Törn C, Nyström L et al (2004) Normal weight promotes remission and low number of islet antibodies prolong the duration of remission in type 1 diabetes. Diabet Med $21: 447-455$

47. Schölin A, Björklund L, Borg H et al (2004) Islet antibodies and remaining $\beta$-cell function eight years after diagnosis of autoimmune diabetes in young adults. A prospective follow-up of the nationwide Diabetes Incidence Study in Sweden (DISS). J Intern Med 255:384-391 